\title{
Knowledge, Attitude and Practices of Dental Adhesives use among Dental Practitioners of Chitwan
}

\author{
Thakur $\mathrm{SN}^{1}$, Khanal B ${ }^{2}$, Chaulagain $\mathrm{R}^{3}$, Shrestha $\mathrm{P}^{4}$, Maharjan $\mathrm{A}^{5}$, Singh $\mathrm{H}^{6}$ \\ ${ }^{1}$ Assistant Professor, Department of Prosthodontics and Maxillofacial Prosthetics, Chitwan Medical College, Bharatpur, \\ Nepal \\ ${ }^{2}$ Assistant Professor, Department of Prosthodontics and Maxillofacial Prosthetics, Chitwan Medical College, Bharatpur, \\ Nepal \\ ${ }^{3}$ Assistant Professor, Department of Oral Pathology, Chitwan Medical College, Bharatpur, Nepal \\ ${ }^{4}$ Dental Surgeon, Chitwan Medical College, Bharatpur, Nepal \\ ${ }^{5}$ Dental Consultant, Patan Acadmey of Health Sciences, Kathmandu, Nepal \\ ${ }^{6}$ Assistant Professor, Department of Community Dentistry, Chitwan Medical College, Bharatpur, Nepal
}

\begin{abstract}
Introduction: Denture adhesive (DA) is defined as a material used to adhere a denture to the oral mucosa. It plays an important role in the retention and the functional comfort among denture wearers. There are conflicting views in dentistry regarding the use of denture adhesives in clinical practice. Therefore, the main purpose of the study is to reveal the knowledge, attitude and practices regarding denture adhesives among the dental practitioners of Chitwan district, Nepal.

Materials and Methods: A 20 item questionnaire was distributed among the registered dental practitioners of Chitwan districts using online google forms and the printed questionnaires were distributed personally to the practitioners who were accessible. Data were entered into Microsoft 2007 excel sheet and descriptive statistical analysis was done using SPSS version 20.

Results: The results showed that $69.1 \%$ of General dental practitioners and $50 \%$ of other specialists had average knowledge while all the prosthodontics had good knowledge regarding denture adhesives. About $96.80 \%$ of General dental practitioners, $60 \%$ of other specialists frequently use denture adhesive in their practice. Only $20.2 \%$ of general dental practitioners and $20 \%$ of other specialists knew the adverse effects of zinc-containing denture adhesives. Most of the dental practitioners (93\%) used powder form of denture adhesives.

Conclusion: Most of the dental practitioners of Chitwan had fair knowledge, attitude and practice regarding denture adhesives.
\end{abstract}

Key words: Attitude; Denture Adhesives; Knowledge; Practice; Questionnaire.

\section{Introduction}

$\mathrm{D}$ enture adhesives (DAs) are defined as the material used to adhere a denture to the oral mucosa. ${ }^{1}$ The American College

Conflict of Interest: No

\section{*Corresponding Author}

Dr. Smriti Narayan Thakur

Assistant Professor, Department of Prosthodontics

and Maxillofacial Prosthetics, Chitwan Medical

College, Bharatpur, Nepal

Email Id: maxillofacial1981@gmail.com of Prosthodontists published evidence-based guidelines regarding the use of denture adhesives and concluded that DAs improve the retention, stability, masticatory function, sealing out of food particles, and overall function of dentures. $^{2-5}$

DAs enhance the quality of life of edentulous patients. However, less research is available regarding the long term effects of the use of DAs on oral tissue health. ${ }^{3,5}$ Despite of this fact DAs have been accepted by denture wearers 
worldwide, but most of the Prosthodontics, educators \& dental professionals have been reluctant to use these over the counter products. ${ }^{6,7}$ The use of DAs is still a controversial topic in clinical practice and academia. The conflicting aspects of DAs are classified into two approaches; traditional historical and advocate approaches. The traditional historical approach specified that the use of DAs reflects the inadequate clinical skills \& lack of prosthetic expertise but the advocated approach considers that DAs facilitate fabrication \& post insertion phases in denture prosthesis service..$^{7,8}$

Several questionnaire-based studies have been performed in various countries, the results showed several diversifications regarding the knowledge, attitude \& practices of DAs among the dental practitioners. ${ }^{9-12}$ The purpose of this study was to reveal the viewpoints and approaches of dentists regarding denture adhesive use through questionnaires. Such information could serve to disclose both the range and distribution of professional opinions and beliefs of dentists on the topic of denture adhesives.

\section{Materials \& Methods}

The descriptive, cross-sectional study was conducted among the registered dental practitioners of Chitwan district from $26^{\text {th }}$ Janauary 2020 to $26^{\text {th }}$ Feburary 2020. Before data collection, the study was approved by the Institutional Review Committee of Chitwan Medical College (Ref No.-CMCIRC/076/077-115).

The data collection tool was a structured questionnaire, which was adopted from the previous study ${ }^{12} \&$ modified after the consultation with experts related to the field. The pretesting of the questionnaire was conducted among 30 dental practitioners outside of Chitwan. Based on pretest results, modifications were made and the final questionnaire was prepared.
The questionnaire consisted of 20 items \& divided into four parts. The first part constituted of sociodemographic details of participants (age, gender, educational qualifications, and years of experience. The second part constituted of nine questions related to knowledge regarding denture adhesives (composition, mechanism, indications and contraindications). The modified Bloom's cut-off points, 80\%-100\%, 50\%-79\%, and $<50.0 \%$, were adapted and were considered good knowledge, average knowledge, and poor knowledge respectively The third part of the questionnaire contained six questions related to attitudes. The options for attitudes were based on a 5 point Likert Scale. It requires the dentists to decide on their level of agreement along this scale (Strongly disagree, disagree, don't know, agree \& strongly agree). The fourth part of the questionnaire contained five practice questions (clinical practice, patient recall \& evaluation) were included.

The convenience sampling method was used to collect the data. The two methods were adopted to send the questionnaire to participants using google forms through the mail and printed questionnaires personally who were accessible. All filled forms \& those who consented were included in the study.

All returned questionnaires were checked for completeness, inconsistencies of response manually coded \& entered into Microsoft excel sheet \& descriptive statistical analysis (frequency and percentage) was done using SPSS version 20.0 (IBM Corporation, Armonk, NY, USA).

\section{Results}

The questionnaires were distributed among 140 dental practitioners but only 120 filled questionnaires were received in this study with a response rate of $85.71 \%$. The Sociodemographic individualities of the study subjects are shown in (Table 1). The majority of 
the dentists were females $(73.3 \%)$ and most of the study population belonged to general dental practitioners $(78.3 \%)$.

Dentist's knowledge status associated with the use of denture adhesive in denture therapy is presented in Table 2. As presented in this table, when participants were questioned regarding knowledge related questions $69.1 \%$ of general dental practitioners had average knowledge but $50 \%$ of the other specialists had average and $50 \%$ had poor knowledge regarding denture adhesives.

When participants were asked to identify the wrong mechanism of action among the given options, $53.2 \%$ of general dental practitioners, $100 \%$ Prosthodontics, and $40 \%$ of other specialists successfully identified the wrong answer (Figure 1). Amixed response was elicited when the dental practitioners were asked about the use of denture adhesives among patients with Xerostomia (Figure 2). Among the participants, only $20.2 \%$ general dental practitioners, $20 \%$ other specialists \& $100 \%$ prosthodontics were aware of neurological disease due to prolonged use of Zinc containing denture adhesives.

When participants were asked the questions related to attitude regarding the use of denture adhesive, denture adhesives were means to improve retention in improperly fabricated dentures according to $8.5 \%$ of general dental practitioners \& $20 \%$ of other specialists strongly agreed. Only $30.9 \%$ of general dental practitioners \& $20 \%$ of other specialists agreed that prescribing denture adhesives indicates inadequate skills of the clinician to fabricate dentures. Among the participants, $28.7 \%$ of general dental practitioners \& $70 \%$ of other specialists were not aware that denture adhesives improve mastication efficacy in denture wearers (Table 3).

More than $96.80 \%$ of general dental practitioners $\& 60 \%$ of other specialists had used denture adhesives in their clinical practices (Table4). The powder type of denture adhesives was more commonly used by $93.6 \%$ of general dental practitioners. About $62.8 \%$ of General dental practitioners, $100 \%$ prosthodontics, and $30 \%$ of other specialists used denture adhesives to stabilize the trial base during jaw relations (Figure 3). More than $90.43 \%$ of General dental practitioners, $60 \%$ of other specialists recalled dental patients using denture adhesives (Table 4). Only $63.8 \%$ of General dental practitioners, $40 \%$ of other specialists cleaned the denture whenever old denture wearers reported to their clinic (Table 4).

Table 1: Sociodemographic Individualities of the Participants N (\%), N=120

\begin{tabular}{|l|c|}
\hline Variables & N (\%) \\
\hline Gender & $32(26.7 \%)$ \\
\hline Male & $88(73.3 \%)$ \\
\hline Female & \\
\hline Qualification & $94(78.3 \%)$ \\
\hline General Dental Practitioner & $6(5 \%)$ \\
\hline Prosthodontics & $20(16.7 \%)$ \\
\hline Other Specialists & \\
\hline Year of Clinical Experience & $107(89.2 \%)$ \\
\hline $1-10$ years & $11(9.2 \%)$ \\
\hline $11-20$ years & $2(1.7 \%)$ \\
\hline$>20$ years & \\
\hline
\end{tabular}


Table 2: Participant's knowledge status associated with use of denture adhesives in denture therapy $\mathrm{N}(\%) \mathrm{N}=120$.

\begin{tabular}{|l|c|c|c|c|}
\hline \multicolumn{4}{|c|}{ Knowledge Status } \\
\hline Qualification & $\begin{array}{c}\text { Good } \\
\text { Knowledge }\end{array}$ & $\begin{array}{c}\text { Average } \\
\text { Knowledge }\end{array}$ & Poor Knowledge & Total \\
\hline General Dental Practitioners & $11(11.7 \%)$ & $65(69.1 \%)$ & $18(19.1 \%)$ & $94(100 \%)$ \\
\hline Prosthodontics & $6(100 \%)$ & $0(0 \%)$ & $0(0 \%)$ & $6(100 \%)$ \\
\hline Other Specialists & $0(0 \%)$ & $10(50 \%)$ & $10(50 \%)$ & $20(100 \%)$ \\
\hline Total & $\mathbf{1 7}(\mathbf{1 4 . 2 \% )}$ & $\mathbf{7 5 ( 6 2 . 5 \% )}$ & $\mathbf{2 8}(\mathbf{2 3 . 3 \% )}$ & $\mathbf{1 2 0}(\mathbf{1 0 0} \%)$ \\
\hline
\end{tabular}

Table 3: Participant's attitudes related to the use of denture adhesives $N(\%) N=120$

\begin{tabular}{|l|c|c|c|c|c|}
\hline \multirow{2}{*}{ Questions } & \multicolumn{5}{c|}{ N(\%) of respondents N= 120 } \\
\cline { 2 - 5 } & Strongly agree & Agree & Do not know & Disagree & Strongly Disagree \\
\hline 1.Denture adhesive is used to provide retention to improperly fabricated or ill-fitting denture \\
\hline General Dental Practitioners & $8(8.5 \%)$ & $11(11.7 \%)$ & $18(19.1 \%)$ & $19(20.1 \%)$ & $38(40.4 \%)$ \\
\hline Prosthodontics & $0(0 \%)$ & $0(0 \%)$ & $0(0 \%)$ & $0(0 \%)$ & $6(100 \%)$ \\
\hline Other Specialists & $4(20 \%)$ & $4(20 \%)$ & $0(0 \%)$ & $0(0 \%)$ & $12(60 \%)$ \\
\hline 2. Patients with poor oral hygiene maintenance should not use denture adhesives. \\
\hline General Dental Practitioners & $66(70.2 \%)$ & $9(9.6 \%)$ & $15(16 \%)$ & $2(2.1 \%)$ & $2(2.1 \%)$ \\
\hline Prosthodontics & $6(100 \%)$ & $0(0 \%)$ & $0(0 \%)$ & $0(0 \%)$ & $0(0 \%)$ \\
\hline Other Specialists & $0(0 \%)$ & $12(60 \%)$ & $6(30 \%)$ & $2(10 \%)$ & $0(0 \%)$ \\
\hline 3.Prescribing denture adhesive indicates inadequate skills of the clinician to fabricate dentures \\
\hline General Dental Practitioners & $4(4.3 \%)$ & $29(30.9 \%)$ & $13(13.8 \%)$ & $46(48.9 \%)$ & $2(2.1 \%)$ \\
\hline Prosthodontics & $0(0 \%)$ & $0(0 \%)$ & $0(0 \%)$ & $6(100 \%)$ & $0(0 \%)$ \\
\hline Other Specialists & $0(0 \%)$ & $4(20 \%)$ & $2(10 \%)$ & $12(60 \%)$ & $2(10 \%)$ \\
\hline 4.More the amount of denture adhesive used better is the retention of the denture & \\
\hline General Dental Practitioners & $6(6.4 \%)$ & $16(17 \%)$ & $0(0 \%)$ & $15(16 \%)$ & $57(60.6 \%)$ \\
\hline Prosthodontics & $0(0 \%)$ & $0(0 \%)$ & $0(0 \%)$ & $0(0 \%)$ & $6(100 \%)$ \\
\hline Other Specialists & $0(0 \%)$ & $6(30 \%)$ & $6(30 \%)$ & $8(40 \%)$ & $0(0 \%)$ \\
\hline 5. Denture adhesives cause tissue changes & \multicolumn{5}{|c|}{} \\
\hline General Dental Practitioners & $5(5.3 \%)$ & $75(79.8 \%)$ & $7(7.4 \%)$ & $5(5.3 \%)$ & $2(2.1 \%)$ \\
\hline Prosthodontics & $0(0 \%)$ & $3(50 \%)$ & $0(0 \%)$ & $3(50 \%)$ & $0(0 \%)$ \\
\hline Other Specialists & $0(0 \%)$ & $14(70 \%)$ & $4(20 \%)$ & $0(0 \%)$ & $2(10 \%)$ \\
\hline 6. Denture adhesives improve mastication in denture wearers & & \\
\hline General Dental Practitioners & $4(4.3 \%)$ & $50(53.2 \%)$ & $27(28.7 \%)$ & $11(11.7 \%)$ & $2(2.1 \%)$ \\
\hline Prosthodontics & $6(100 \%)$ & $0(0 \%)$ & $0(0 \%)$ & $0(0 \%)$ & $0(0 \%)$ \\
\hline Other Specialists & $0(0 \%)$ & $6(30 \%)$ & $14(70 \%)$ & $0(0 \%)$ & $0(0 \%)$ \\
\hline
\end{tabular}

Table 4: Denture adhesives use in their clinical practice N (\%) N=120

\begin{tabular}{|c|c|c|c|}
\hline Questions & General practitioners & Prosthodontists & Other specialists \\
\hline \multicolumn{4}{|c|}{ Do you use denture adhesives in your practice? } \\
\hline Yes & 91 (96.80\%) & $6(100 \%)$ & $12(60 \%)$ \\
\hline No & $3(3.20 \%)$ & $0(0 \%)$ & $8(40 \%)$ \\
\hline \multicolumn{4}{|c|}{ Do you recall patients using denture adhesives periodically } \\
\hline Yes & $85(90.4 \%)$ & $6(100 \%)$ & $16(80 \%)$ \\
\hline No & $9(9.6 \%)$ & $0(0 \%)$ & $4(20 \%)$ \\
\hline \multicolumn{4}{|c|}{ Do you professionally clean old dentures whenever the patients visit your clinic again? } \\
\hline Yes & $60(63.83 \%)$ & $6(100 \%)$ & $8(40 \%)$ \\
\hline No & $34(36.17 \%)$ & $0(0 \%)$ & $12(60 \%)$ \\
\hline
\end{tabular}




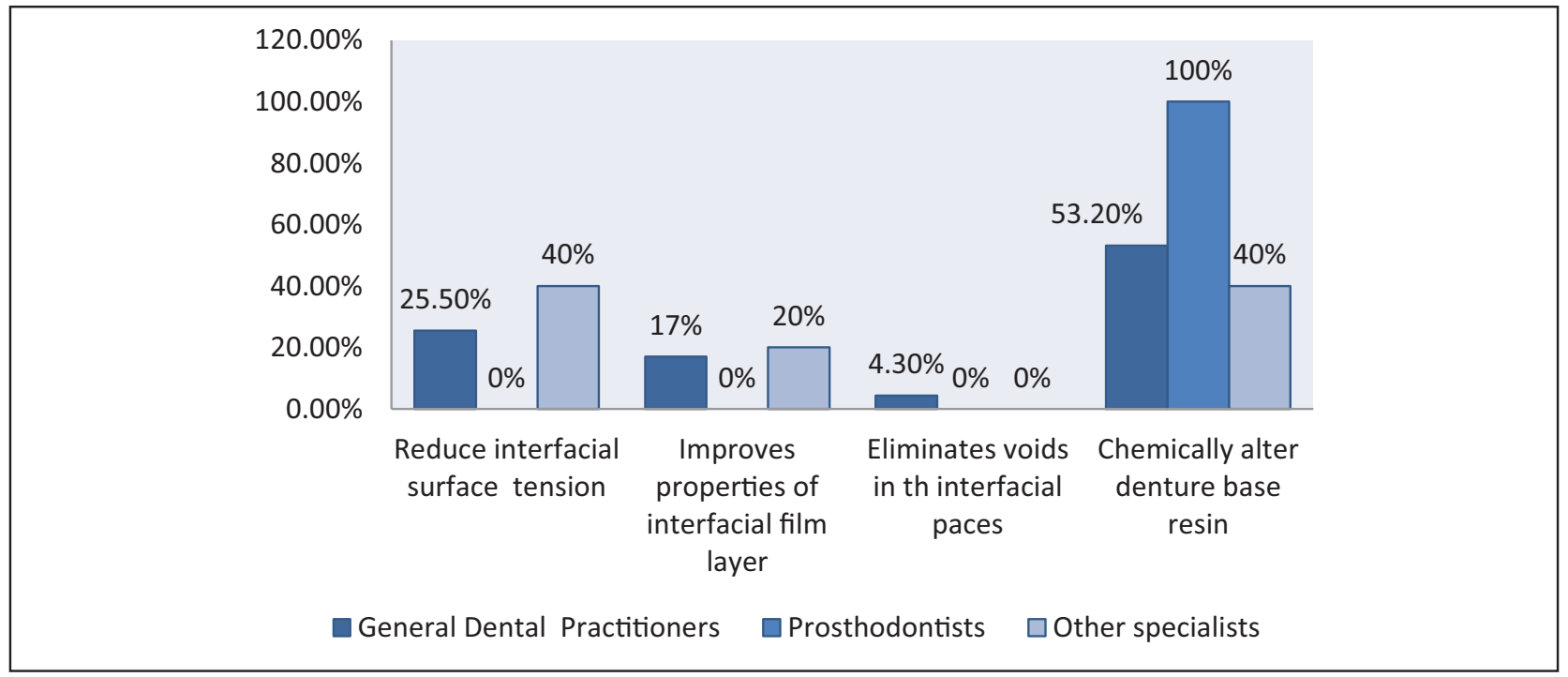

Figure 1: Denture adhesives provide retention by all of the following except

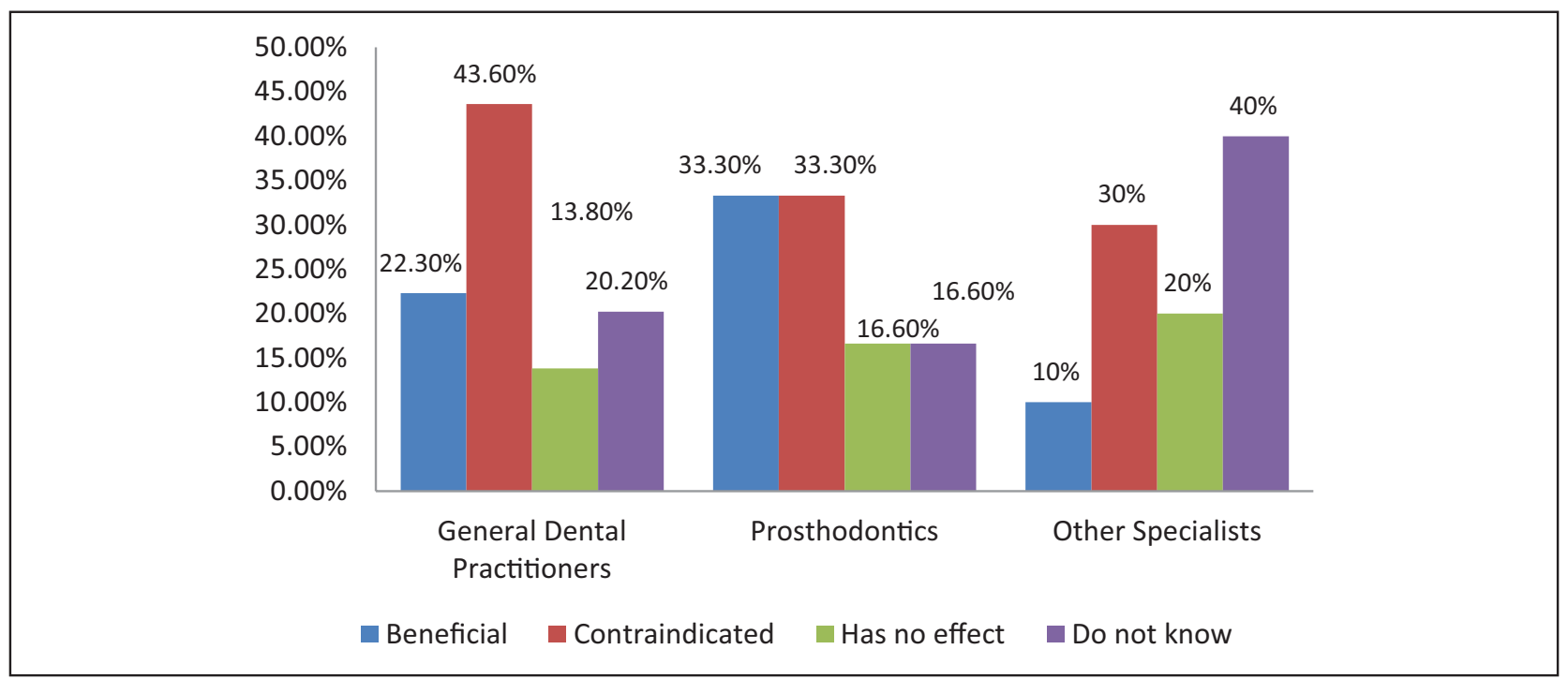

Figure 2: Dental practitioners knowledge regarding the use of denture adhesives inpatient with Xerostomia.

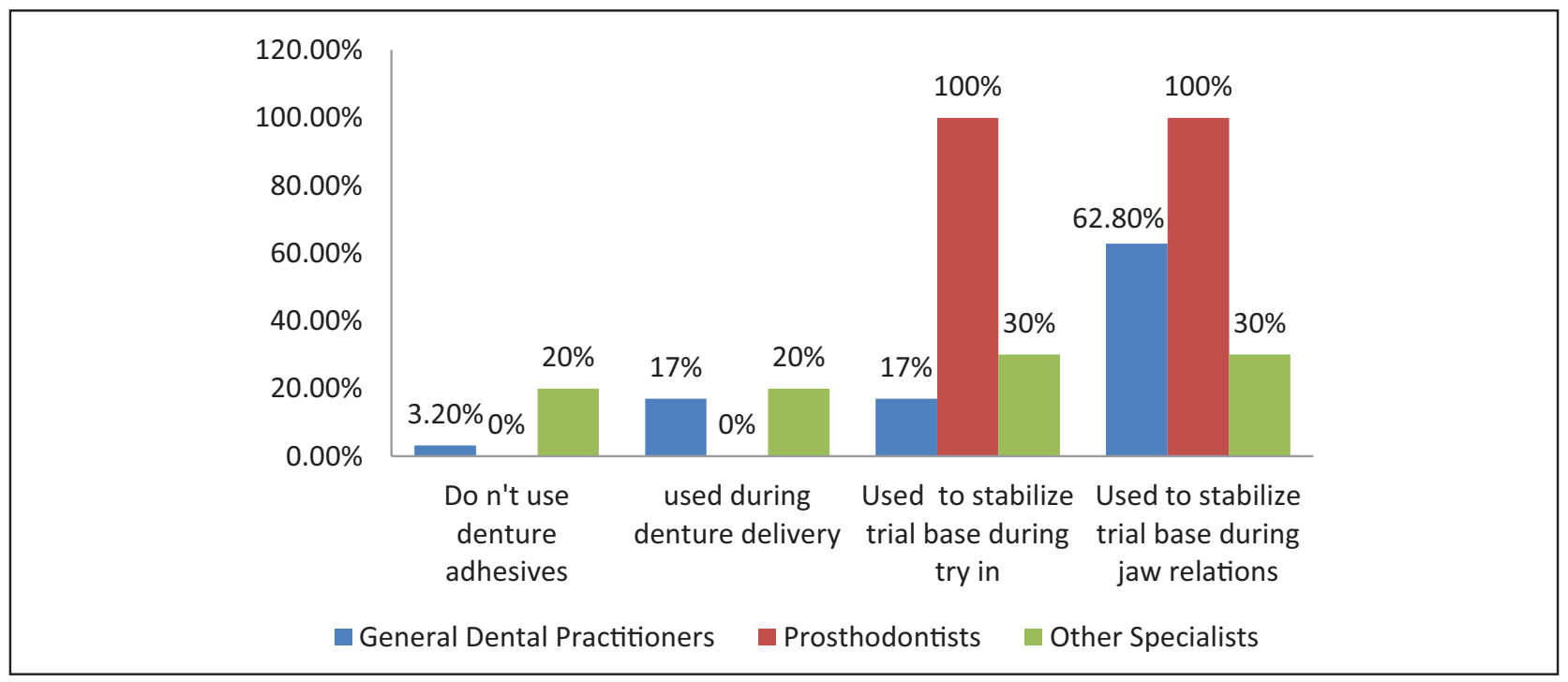

Figure 3: Uses of denture adhesives during denture fabrication steps 


\section{Discussion}

The knowledge regarding denture adhesives is very important for its proper prescription among edentulous patients to increase the acceptance of removable prosthesis. ${ }^{7,13,14}$ About $53.2 \%$ of general dental practitioners responded with the right mechanism of action, so it may cause less misuse of these products.

Denture hygiene is very important \& this study showed that $78.7 \%$ of general dental practitioners were aware that incomplete removal of denture adhesives before reapplication was not good for tissue health. Stafford et.al established that denture adhesives could influence oral flora by causing an imbalance in the flora. ${ }^{15}$ Several past research established that the chronic \& excessive use of zinc-containing denture adhesive results in several neuropathies like paraesthesia, muscle weakness \& ataxic gait. ${ }^{16-18}$ Unfortunately, only $20.2 \%$ of general practitioners and $20 \%$ of other specialists were aware of the adverse effects of zinc-containing denture adhesives in our research. Nations et.al \& Hedera et.al ${ }^{19,20}$ identified that the chronic uses of zinc-containing denture adhesives as a main cause of neuropathy in patients using them. One of the studies established that the overuse of zinc-containing denture adhesives as the main culprit of copper deficiency myelopathy. ${ }^{21,22}$ However, no clinical evidence will be established that zinc-containing denture adhesives result in neuropathy when used according to manufactures instructions. ${ }^{23}$ Zinc free denture adhesives are readily available in the market. ${ }^{23}$ So proper knowledge about zinc-containing denture adhesives among dental practitioners is a must. Patients should be encouraged to take professional advice as well as follow instructions cautiously before using them. The proper use of hydrated denture adhesives provides a cushioning effect on underlying supporting tissues and preventing tissue ulcerations in inpatient with
Xerostomia. ${ }^{24}$ In this study $43.6 \%$ of general dental practitioners, $30 \%$ of other specialists contraindicated the use of denture adhesives in patients with Xerostomia.

Most of the previous studies showed that clinical use of denture adhesives has not yet gained worldwide acceptance due to reasons either less contained of denture adhesives in the undergraduate curriculum or continuing dental education programmes. ${ }^{9,25}$ This study showed that $69.1 \%$ of General dental practitioners \& $50 \%$ of other specialists had average knowledge regarding denture adhesives.so modification of curriculum in undergraduate level \& in continuing dental education programmes are the way to increase the knowledge regarding dental adhesives among dental practitioners.

Attitude is the reflection of knowledge. The result section of this study showed that nearly half of general dental practitioners inconclusive about the indication of denture adhesives for patients wearing improperly fabricated or illfitting dentures. In the above statement, 11.7\% of general dental practitioners \& $20 \%$ of other specialists agreed in contrast to none of the Prosthodontics. The difference in attitude regarding denture adhesive prescription may be due to a difference in curriculum.

In this study, $90.83 \%$ of dental practitioners were using denture adhesives in their clinical practice, this percentage is far above the percentage recorded by Temel $^{26}(56.3 \%)$.

In this study, most of the dental practitioners (62.80\% General dental practitioners, 30\% other specialists, and 100\% Prosthodontists) were using denture adhesives for stabilizing trial bases during jaw relations. This finding was coherent with the consensus which was established by the panel of Prosthodontists $(88 \%)$ in the study by Slaughter et al, ${ }^{8}$ the reason being a stable record base is a prerequisite for recording accurate jaw relations. 
The periodic recall appointments are very much crucial for the evaluation of denture as well as the supporting structure of the edentulous foundation so these guidelines are extremely important for a patient using denture adhesives. ${ }^{19,27} 90.4 \%$ of general dental practitioners and $80 \%$ of other specialists recall their patients using denture adhesives. The timedependent changes in denture bearing foundation occur so every dentist must periodically recall denture wearing patients for evaluation of residual ridge resorption, prosthetic tooth wear, condition of denture bearing tissues as well as systemic health, oral cancer screening. ${ }^{16}$

Several studies established that the periodic professional cleaning of old dentures is one of the techniques to minimize the microbial colonization indenture as well as reduce the chance of respiratory illness in denture wearer patients. ${ }^{28-31}$ In this study $63.8 \%$ of General dental practitioners, $40 \%$ of other specialists cleaned the old dentures whenever the patients reported to their clinic.

The main limitation of the study is that the numbers of participants are limited so the anticipation of the results is restricted and cannot be generalized to other region. Another limitation of the study is the information bias too. Further studies should address this gap by covering a wider geography and an increased number of dentists.

\section{Conclusions}

It can be concluded that denture adhesives are frequently used by dental practitioners. Knowledge about proper indication, contraindications, instructions guidelines to patients and periodic follow up are essential attributes for better management of denture wearing patients. So continuing education courses are essential to get updated knowledge about using denture adhesives in clinical practice and provide the standard care for prosthodontics patients.

\section{Acknowledgments}

The author would like to extend sincere thanks to all the dental practitioners who participated in this study.

\section{References}

1. The glossary of prosthodontic terms. J Prosthet Dent. 2005;94(1):10-92.

2. Felton D, Cooper L, Duqum I, Minsley G, Guckes A, Haug S, Meredith P, Solie C, Avery $\mathrm{D}$, Deal Chandler N. Evidence-based guidelines for the care and maintenance of complete dentures: A publication of the American College of Prosthodontists. Journal of Prosthodontics: Implant, Esthetic and Reconstructive Dentistry. 2011 Feb;20: S1-2.

3. Duqum I, Powers KA, Cooper L, Felton D. Denture adhesive use in complete dentures: clinical recommendations and review of the literature. General dentistry. 2012;60(6):467.

4. Papadiochou S, Emmanouil I, Papadiochos I. Denture adhesives: a systematic review. J Prosthet Dent 2015; 113:391-7.

5. de Oliveira Junior NM, Rodriguez LS, Mendoza Marin DO, Paleari AG, Pero AC, Compagnoni MA. Masticatory performance of complete denture wearers after using two adhesives: a crossover randomized clinical trial. J Prosthet Dent 2014; 112:1182-7.

6. Grasso JE. Denture adhesives. Dent Clin North Am 2004; 48:721-33.

7. Grasso JE. Denture adhesives: changing attitudes. J Am Dent Assoc 1996; 127:90-6.

8. Slaughter A, Katz RV, Grasso JE. Professional attitudes toward denture adhesives: A Delphi technique survey of academic prosthodontists. J Prosthet Dent 1999; 82(1):80-9.

9. Koksal T, Dikbas I, Ozkurt Z, Bal B, Kazaoglu E. A survey of dentists' attitudes toward denture adhesives. OHDMBSC 2007; 6:33-9.

10. Fakhri H, Fayaz A, Faramarzi, Javaheri HH. The knowledge and attitude of general dentists toward denture adhesives in Tehran. Indian $\mathrm{J}$ Dent Res 2009; 20:164-8. 
11. Muneer MU, Ahmed AR, Kamran MF. Awareness of dentists and complete denture wearers towards denture adhesives. Pak Oral Dent J 2013; 33:192-4.

12. Mantri S, Vinay S, Deogade S, Mishra P, Galav A, Sharma K. Knowledge, attitude and practices of denture adhesives use among private dental practitionersof Jabalpur city, Madhya Pradesh: a cross sectional survey. J Indian Prosthodont Soc 2014; 14:243-50.

13. Adisman IK. The use of denture adhesive as an aid to denture treatment. The Journal of prosthetic dentistry. 1989 Dec 1;62(6):711-5.

14. Shay K. Denture adhesives: choosing the right powders and pastes. J Am Dent Assoc. 1991; 122:70-6.

15. Stafford GD, Russell C. Efficiency of denture adhesives and their possible influence on oral microorganisms. J Dent Res. 1971;50(4):832-6.

16. Felton D, Cooper L, Duqum I, Minsley G, Guckes A, Haug S, Meredith P, Solie C, Avery D, Deal Chandler N. Evidence-based guidelines for the care and maintenance of complete dentures: A publication of the American College of Prosthodontists. Journal of Prosthodontics: Implant, Esthetic and Reconstructive Dentistry. 2011 Feb;20: S1-2.

17. Lamb DJ. Denture adhesives: a side effect. Journal of Dentistry. 1980 Jan 1;8(1):35-42.

18. Zhao K, Cheng XR, Chao YL, Li ZA, Han GL. Laboratory evaluation of a new denture adhesive. Dental Materials. 2004 Jun 1;20(5):419-24.

19. Nations SP, Boyer PJ, Love LA, Burritt MF, Butz JA, Wolfe GI, Hynan LS, Reisch J, Trivedi JR. Denture cream: an unusual source of excess zinc, leading to hypocupremia and neurologic disease. Neurology. 2008 Aug 26;71(9):639-43.

20. Hedera P, Peltier A, Fink JK, Wilcock S, London Z, Brewer GJ. Myelopolyneuropathy and pancytopenia due to copper deficiency and high zinc levels of unknown origin II. The denture cream is a primary source of excessive zinc. Neurotoxicology. 2009 Nov 1;30(6):996-
9.

21. Doherty K, Connor M, Cruickshank R. Zinccontaining denture adhesive: a potential source of excess zinc resulting in copper deficiency myelopathy. British Dent J. 2011 Jun;210(11):523-5.

22. Shammaa Y, Rodgers J. Denture fixative cream and the potential for neuropathy. Dental update. 2012;39(8):575-7.

23. Jagger R, King E. Denture Adhesives-Best Practice. Dental Update. 2020;47(1):38-42.

24. Shay K. The retention of complete dentures. Boucher's prosthodontic treatment for edentulous patients. 1997:400-11.

25. Özcan M, Kulak Y, Arikan A, Silahtar E. The attitude of complete denture wearers towards denture adhesives in Istanbul. J Oral Rehab. 2004;31(2):131-4.

26. Temel K. 'A survey of dentists' attitudes toward Denture Adhesives". OHDMBSC-Vol.1 Martie;33-9.

27. Woelfel JB, Winter CM, Curry RL. Additives sold over the counter dangerously prolong wearing period of ill-fitting dentures. J Am Dent Assoc. 1965;71(3):603-13.

28. Kokubu K, Senpuku H, Tada A, Saotome Y, Uematsu H. Impact of routine oral care on opportunistic pathogens in the institutionalized elderly. J Med Dent Sci. 2008;55(1):7-13.

19. Ishikawa A, Yoneyama T, Hirota K, Miyake Y, Miyatake K. Professional oral health care reduces the number of oropharyngeal bacteria. J Dent Res. 2008;87(6):594-8.

30. Barnes CM. Dental hygiene intervention to prevent nosocomial pneumonias. Journal of Evidence Based Dental Practice. 2014 Jun 1; 14:103-14.31. Sharma A, Shrestha B, Chaudhari BK, Singh RK, Suwal P. A Comparative Study of Microorganisms Adhered to Different Surfaces of Temporary Removable Partial Dentures. J Nep Prosthodont Soc. 2018;1(1):12-7. 